\title{
CONSTRUINDO LEIS: OS CONSTRUTORES E AS CONCESSÕES DE SERVIÇOS*
}

WAGNER PRALON MANCUSO

A sanção da lei $n^{\circ} 8987$ - a Lei das Concessões - foi a decisão que inaugurou a extensa série de iniciativas tomadas sob o governo de Fernando Henrique Cardoso (1995-2002) para reduzir a atuação direta do poder público como produtor de bens e prestador de serviços. De fato, a lei que regulamenta a concessão de serviços públicos no Brasil foi sancionada por Cardoso em 13 de fevereiro de 1995, pouco mais de um mês após sua posse como presidente da república. A sanção da lei culminou um processo de tramitação que durou mais de quatro anos e que remonta a outubro de 1990, quando o próprio Cardoso, então senador pelo Estado de São Paulo, apresentou um projeto de lei para regulamentar o tema.

A lei das concessões é o documento que determina todos os direitos e as obrigações do poder concedente (governo federal, estadual, municipal ou do Distrito Federal), dos concessionários e dos usuários de serviços públicos. Ela reúne também as regras relativas à tarifa a ser cobrada pelos concessionários e ao processo de licitação que deve ser seguido pelo poder concedente ao realizar uma concessão. Ela estabelece ainda o conteúdo que deve constar nos contratos de concessão que forem celebrados.

\footnotetext{
* O presente artigo é baseado na dissertação de Mestrado "A indústria da construção e a legalização das concessões de serviços públicos", defendido em fevereiro de 2000 junto ao Departamento de Ciência Política da USP. A pesquisa faz parte do Projeto Integrado "As novas fronteiras do Estado: privatização em perspectiva comparada", coordenado pela professora Maria Hermínia Tavares de Almeida e financiado pelo CNPq e pela FAPESP, que também concedeu ao autor bolsa de Mestrado.
} 
O objeto deste artigo é o comportamento assumido pelas entidades que representam os interesses da indústria da construção durante o processo de elaboração das regras que regem a concessão de serviços públicos no Brasil. Procuro mostrar que dois conceitos centrais da teoria da ação coletiva formulada pelo economista norte-americano Mancur Olson (1999 [1965]) - os conceitos de carona e de exploração do grande pelo pequeno - ajudam a explicar o comportamento daquelas entidades. A base teórica do artigo é apresentada na primeira seção.

Os dados apresentados na segunda seção deste artigo indicam que as concessões de serviços públicos, principalmente as concessões de rodovias e de saneamento básico, ofereceram muitas oportunidades de negócios que foram aproveitadas pelos construtores, não somente aqueles que se encontravam entre os maiores do país durante a tramitação da legislação sobre concessões, mas também para aqueles de menor porte. É razoável supor, portanto, que todas as entidades da indústria da construção que identificavam as concessões de serviços públicos como uma fonte de oportunidades de negócios para as empresas filiadas tinham fortes motivos para se envolverem na elaboração da legislação sobre concessões. A segurança que a legislação sobre concessões poderia proporcionar para as filiadas que quisessem tornar-se concessionárias era um benefício coletivo de interesse direto pelo qual, naturalmente, deveriam pugnar. No entanto, no universo formado por dezenas de entidades, o trabalho de articulação dos interesses da indústria da construção ficou concentrado em duas organizações.

A terceira seção do artigo mostra que a maior parte do trabalho foi realizada pela Associação das Construtoras de Centrais Energéticas (ACCE), uma organização que reunia algumas das maiores empresas construtoras do país. O Sindicato da Indústria da Construção Civil de Grandes Estruturas do Estado de São Paulo (SINDUSCON/SP) também desenvolveu atividades de lobby, embora com menos freqüência do que a ACCE.

A última seção do artigo sintetiza os resultados da análise. Além disso, situa este trabalho como uma contribuição para o estudo geral da articulação dos interesses do empresariado ao longo do processo de produção legislativa de nível federal. Argumento que o lobby empresarial é uma atividade que ocorre nos diversos estágios que compõem o processo de produção legislativa; que se expressa concretamente em várias formas e que leva em conta o papel preponderante que o Poder Executivo exerce na produção legislativa brasileira. 


\section{A LÓGICA DA AÇÃO COLETIVA}

A Lógica da Ação Coletiva, de Mancur Olson, é uma obra que tem exercido grande impacto sobre a ciência política contemporânea. O objeto de Olson é o comportamento de indivíduos racionais que formam um grupo e têm interesse na obtenção de um benefício coletivo. Olson define indivíduo racional como o indivíduo que procura realizar seus objetivos por meios "eficientes e efetivos" (1999:77). Qualquer objetivo, desde o mais egoísta até o mais altruísta, pode ser perseguido de forma racional. Mas Olson focaliza especificamente o comportamento de indivíduos racionais que formam aquilo que chama de "grupos econômicos", ou seja, grupos cujos membros têm interesse na obtenção de benefícios coletivos que resultem em vantagens materiais para si próprios. Olson define benefício coletivo como o benefício que, se for consumido por qualquer pessoa $\mathrm{Xi}$ em um grupo $\mathrm{X} 1, \ldots, \mathrm{Xi}, \ldots, \mathrm{Xn}$, não pode viavelmente ser negado aos outros membros desse grupo" (1999: 26).

A idéia central de Olson é que o interesse comum dos membros de um grupo pela obtenção de um benefício coletivo nem sempre é suficiente para levar cada um deles a contribuir para a obtenção desse benefício. Há circunstâncias em que o indivíduo racional, buscando maximizar seu próprio bem-estar, prefere que os outros membros do grupo paguem o custo da obtenção do benefício coletivo para, assim, poder gozar das vantagens dele oriundas sem ter gasto nada. A decisão de todo indivíduo racional sobre se irá ou não contribuir para a obtenção do benefício coletivo (e, em caso de decisão positiva, sobre o volume da sua contribuição) depende de um cálculo, onde o indivíduo considera: a) o custo marginal de fornecer o benefício coletivo em alguma medida ${ }^{1}$; b) o benefício marginal oriundo do fornecimento do benefício coletivo em alguma medida e c) a quantidade do benefício coletivo já fornecida. Se houver no grupo um indivíduo (indivíduo A) para o qual os benefícios pessoais oriundos do fornecimento de certa quantidade do bem coletivo (quantidade $\mathrm{X}$ ) superam os custos de fornecê-la, então será vantajoso para ele o fornecimento daquela quantidade determinada do bem coletivo, mesmo que tenha que arcar sozinho com todos os custos do fornecimento. Esse indivíduo seguirá con-

${ }^{1} \mathrm{Na}$ teoria de Olson vários níveis ou quantidades do benefício coletivo podem ser atingidos e a provisão do benefício coletivo nem sempre é, simplesmente, uma questão de "tudo ou nada" (Moe 1988: 263). Olson freqüentemente utiliza a expressão "determinada quantidade do benefício coletivo" (ver, por exemplo, 1999: 46). 
tribuindo com a obtenção do bem coletivo até que o custo marginal de produzir unidades do bem coletivo se iguale ao benefício marginal delas oriundo. Se para algum outro membro do grupo (indivíduo B) os benefícios pessoais oriundos do fornecimento de certa quantidade adicional do bem coletivo (quantidade $\mathrm{Y}$ ) superam os custos, será vantajoso para esse indivíduo B dividir de alguma forma com o indivíduo A os custos do fornecimento da quantidade $\mathrm{X}$ do bem coletivo e fornecer a quantidade complementar Y, mesmo que tenha que arcar sozinho com todos os custos do fornecimento de Y. Tal como o indivíduo A, também o indivíduo B seguirá contribuindo até que o custo marginal de produzir unidades adicionais do bem coletivo se iguale ao benefício marginal delas oriundo. É importante notar que, se o indivíduo B contribuir antes que o indivíduo A para o fornecimento do benefício coletivo, o indivíduo A não terá incentivo para fazer qualquer contribuição.

Os membros do grupo para os quais o custo de produzir qualquer quantidade do bem coletivo excede os benefícios irão pegar carona na ação do indivíduo A e do indivíduo B. Como o bem fornecido por A e B é coletivo, os demais indivíduos se beneficiarão dele sem terem contribuído para sua obtenção. Ou seja, Olson utiliza o termo carona para designar a atitude de indivíduos racionais e auto-interessados que, mesmo considerando desejável a obtenção de um benefício coletivo, não se dispõem a colaborar para ela, pois esperam que outros indivíduos o façam. Os caroneiros preferem que outros indivíduos arquem com as despesas da obtenção do benefício coletivo, para que, desta forma, possam usufruir as vantagens dele procedentes sem terem que investir seus próprios recursos.

A grande assimetria entre os membros de um grupo no que diz respeito aos seus níveis de interesse por um benefício coletivo pode dar origem a um fenômeno inusitado: a exploração do grande pelo pequeno. A exploração ocorre quando o membro grande ${ }^{2}$ assume uma parte do custo do provimento do bem coletivo que é proporcionalmente maior do que a parte que lhe cabe das vantagens proporcionadas por esse bem coletivo. O membro pequeno possui dois motivos para explorar o membro maior: em primeiro lugar porque, por definição, ele sempre alcança uma parcela do benefício gerado por qualquer quantidade do bem coletivo que é menor do que a parcela alcançada pelo membro maior. Dessa forma, o membro menor tem menos incentivo para fornecer qualquer quantidade do bem coletivo do que o mem-

2 "Aquele [membro do grupo] que, mesmo que fosse por sua própria conta, proveria a maior quantidade do benefício coletivo" (Olson 1999: 47). 
bro maior. Em segundo lugar porque, sempre que o membro menor alcança gratuitamente sua parcela do benefício total gerado pela quantidade do bem coletivo fornecida pelo membro maior, ele alcança mais do que teria alcançado se fornecesse por si próprio alguma quantidade do bem coletivo ${ }^{3}$. Sendo assim, o membro menor não tem qualquer incentivo para fornecer novas quantidades do bem coletivo às suas próprias custas.

Os dados apresentados na seção seguinte mostram que as concessões de serviços públicos - especialmente as concessões de estradas e de saneamento básico - criaram oportunidades que foram aproveitadas por muitos construtores de porte variado. Todas as entidades da indústria da construção que sabiam reconhecer nessas oportunidades um mercado potencial para seus filiados tiveram motivos fortes para se envolverem na elaboração da legislação sobre concessões. Através desse envolvimento, as entidades poderiam tentar garantir a aprovação de regras que proporcionassem a segurança adequada para os construtores que quisessem tornar-se concessionários. A segurança a ser proporcionada pela legislação sobre concessões é um benefício coletivo que interessa a todos os construtores que pretendem ser concessionários de serviços públicos. A existência de regras que tratam com clareza das questões relativas às concessões é de fato vantajosa para todos os que planejam obtê-las, pois dessa forma podem tomar suas decisões com base em projeções confiáveis de cenários futuros. A segurança proporcionada pela legislação referente às concessões é um benefício coletivo marcado pela impossibilidade de exclusão, pois sua fruição não pode ser recusada a qualquer concessionário - real ou potencial. Por outro lado, é um benefício coletivo caracterizado por total partilhabilidade, pois pode ser usufruído por qualquer concessionário real ou potencial - sem nenhuma redução das oportunidades de fruição disponíveis para os outros concessionários.

$\mathrm{Na}$ terceira seção deste artigo eu procuro mostrar que o comportamento efetivamente assumido pelas entidades da construção durante a elaboração da legislação sobre concessões parece indicar que ocorreram dois fenômenos previstos pela teoria olsoniana: a carona e a exploração do grande pelo pequeno ${ }^{4}$.

${ }^{3}$ Como foi visto anteriormente, o indivíduo racional contribui para a obtenção do bem coletivo até que o custo marginal de produzir unidades do bem coletivo se iguale ao benefício marginal delas oriundo. O membro maior tem incentivo para fornecer mais unidades do bem coletivo do que o membro menor.

${ }^{4}$ Em The Logic of Collective Action, Olson focaliza o comportamento de indivíduos. No entanto, o próprio autor utiliza a teoria desenvolvida naquela obra para explicar o comportamento de associações (Olson \& Zeckhauser 1966). 


\section{CONCESSÕES E OPORTUNIDADES}

A concessão de serviços públicos à iniciativa privada tem gerado muitas oportunidades de negócios para empresas e grupos empresariais que atuam no ramo da construção. Por um lado, os construtores estão tendo a chance de participar - isoladamente ou em consórcio - de licitações para a prestação direta de serviços públicos. Por outro lado, eles estão tendo o ensejo para oferecer seus serviços especializados às concessionárias privadas incumbidas de realizar investimentos em infra-estrutura.

Os dados apresentados em seguida mostram que muitos construtores estão aproveitando efetivamente as oportunidades de negócios criadas pela política de concessão de serviços públicos à iniciativa privada. As entidades da construção que viam nessas oportunidades um mercado potencial para pelo menos alguns dos seus filiados tinham motivos para tentar intervir na elaboração da legislação sobre concessões e, dessa forma, procurar garantir a segurança das empresas que quisessem tornar-se concessionárias.

Antes de prosseguir, é necessário mencionar que os dados apresentados aqui possuem pelo menos dois limites importantes: a) eles referem-se apenas a alguns dentre muitos serviços públicos passíveis de concessão à iniciativa privada e b) eles não informam sobre os negócios que as concessões propiciaram indiretamente para os construtores, ou seja, não informam sobre os negócios que os construtores fecharam com concessionários privados não-construtores ${ }^{5}$.

O Quadro 1 informa sobre a presença de construtores em concessionárias incumbidas de prestar serviços de recuperação, conservação e operação (às vezes também de ampliação e de outros tipos) de estradas federais, estaduais e municipais 6 .

\footnotetext{
${ }^{5} \mathrm{~A}$ lista completa das concessões mencionadas no artigo e das empresas e grupos construtores que atuam como concessionários pode ser solicitada pelo e-mail: pralon@usp.br

6 Focalizei o momento da assinatura do contrato de concessão. Assim, os quadros a seguir não informam sobre alterações posteriores na composição das concessionárias. Considera-se que há construtores brasileiros nas concessionárias quando o vencedor da licitação é: a) um grupo (ou uma empresa) que atua diretamente no setor de construção; b) uma empresa que, mesmo não atuando diretamente na construção, faz parte de grupo que atua no setor; c) um grupo (ou uma empresa) que tem como acionista um grupo (ou uma empresa) que atua na construção; d) um consórcio que tem como membro pelo menos um grupo (ou uma empresa) que atua na construção; e) um consórcio que tem como membro pelo menos uma empresa que, mesmo não atuando diretamente na construção, faz parte de grupo que atua no setor; f) um consórcio que tem como membro pelo menos um grupo (ou uma empresa) que tenha como acionista um grupo (ou uma empresa) que atua na construção.
} 
QUADRO 1.

Participação de Construtores em Concessões de Estradas Federais, Estaduais e Municipais

\begin{tabular}{|c|c|c|}
\hline \multicolumn{3}{|c|}{ ESTRADAS FEDERAIS } \\
\hline $\begin{array}{l}\text { Concessões realizadas } \\
\qquad 5\end{array}$ & & $\begin{array}{c}\text { Concessionárias com } \\
\text { presença de construtores } \\
5\end{array}$ \\
\hline \multicolumn{3}{|c|}{$\begin{array}{l}\text { ESTRADAS ESTADUAIS } \\
\text { Espírito Santo }\end{array}$} \\
\hline $\begin{array}{l}\text { Concessões realizadas } \\
\qquad 1\end{array}$ & & $\begin{array}{c}\text { Concessionárias } \\
\text { com presença de construtores } \\
1\end{array}$ \\
\hline \multicolumn{3}{|c|}{ Paraná } \\
\hline $\begin{array}{l}\text { Concessões realizadas } \\
6 \\
6\end{array}$ & & $\begin{array}{c}\text { Concessionárias } \\
\text { com presença de construtores } \\
6\end{array}$ \\
\hline \multicolumn{3}{|c|}{ Rio de Janeiro } \\
\hline $\begin{array}{l}\text { Concessões realizadas } \\
1\end{array}$ & & $\begin{array}{c}\text { Concessionárias } \\
\text { com presença de construtores } \\
1\end{array}$ \\
\hline \multicolumn{3}{|c|}{ Rio Grande do Sul } \\
\hline $\begin{array}{l}\text { Concessões realizadas } \\
\qquad 9\end{array}$ & & $\begin{array}{c}\text { Concessionárias } \\
\text { com presença de construtores } \\
9\end{array}$ \\
\hline \multicolumn{3}{|c|}{ Santa Catarina } \\
\hline $\begin{array}{l}\text { Concessões realizadas } \\
3\end{array}$ & & $\begin{array}{c}\text { Concessionárias } \\
\text { com presença de construtores } \\
3\end{array}$ \\
\hline \multicolumn{3}{|c|}{ São Paulo } \\
\hline $\begin{array}{l}\text { Concessões realizadas } \\
\qquad 9\end{array}$ & & $\begin{array}{c}\text { Concessionárias } \\
\text { com presença de construtores } \\
9\end{array}$ \\
\hline \multicolumn{3}{|c|}{$\begin{array}{c}\text { ESTRADAS MUNICIPAIS } \\
\text { Rio de Janeiro }\end{array}$} \\
\hline Concessões realizadas & & $\begin{array}{l}\text { Concessionárias } \\
\text { com presença de construtores }\end{array}$ \\
\hline \multicolumn{3}{|c|}{ TOTAL } \\
\hline Concessões realizadas & & $\begin{array}{c}\text { Concessionárias } \\
\text { com presença de construtores }\end{array}$ \\
\hline 35 & & 35 \\
\hline
\end{tabular}

Fonte: Página da Associação Brasileira das Concessionárias de Rodovias na Internet, janeiro de 2000. 
Foram realizadas, ao todo, trinta e cinco concessões: cinco de estradas federais, vinte e nove de estradas estaduais e uma de estrada municipal. Construtores estão presentes em todas as concessionárias - isoladamente ou em consórcio com outras empresas e grupos.

A Tabela 1 apresenta informações sobre o porte que as empresas construtoras presentes em concessionárias de estradas possuíam durante a tramitação da legislação sobre concessões. Essas informações permitem avaliar se as concessões de estradas geraram oportunidades diretas de negócios apenas para construtores que possuíam porte médio ou grande durante a tramitação da legislação sobre concessões ou se as concessões geraram oportunidades que foram aproveitadas também por construtores de menor porte?

Ao todo, setenta e oito empresas ou grupos empresariais fazem parte das concessionárias de estradas - isoladamente ou em consórcio. Desse total, sessenta (77\%) são construtores.

TABELA 1: Construtores que participam de concessionárias de estradas por porte

\begin{tabular}{cccccc}
\hline $\begin{array}{c}\text { Entre as 100 } \\
\text { maiores apenas } \\
\text { em 1992 (a) }\end{array}$ & $\begin{array}{c}\text { Entre as 100 } \\
\text { maiores apenas } \\
\text { em 1995 (b) }\end{array}$ & $\begin{array}{c}\text { Entre as 100 } \\
\text { maiores nas } \\
\text { duas listas }(c)\end{array}$ & $\begin{array}{c}(\mathrm{a})+(\mathrm{b}) \\
+(\mathrm{c})\end{array}$ & $\begin{array}{c}\text { Em nenhuma } \\
\text { das duas listas }\end{array}$ & TOTAL \\
\hline 04 & 05 & 23 & 32 & 28 & 60 \\
\hline
\end{tabular}

Fontes: Página da Associação Brasileira das Concessionárias de Rodovias na Internet; Revista O Empreiteiro, junho de 1992 e julho de 1995.

A Tabela 1 mostra que trinta e dois construtores que fazem parte de concessionárias de estradas $(53,3 \%$ de 60$)$ figuravam entre os maiores construtores brasileiros em algum momento-chave da tramitação da legislação sobre concessões. Os outros vinte e oito construtores $(46,7 \%)$ eram de menor porte.

O Quadro 2 apresenta informações sobre a presença de construtores em concessionárias incumbidas de prestar serviços de saneamento básico.

Ao todo, foram efetivadas vinte e oito concessões: dezesseis concessões plenas (água e esgoto), cinco apenas do serviço de água e sete ape-

${ }^{7}$ A tabela foi montada a partir do confronto de três listas: a) a lista dos construtores que fazem parte de concessionárias de estradas; b) a lista dos cem maiores construtores brasileiras em 1992 (ano em que foi aprovado pela Câmara dos Deputados o projeto de lei que resultou na lei $n^{\circ}$ 8987/95) e c) a lista dos cem maiores construtores brasileiras em 1995 (ano em que foi aprovado pelo Senado Federal e sancionado pelo presidente da República o projeto de lei que resultou na lei $\mathrm{n}^{\circ}$ 8987). A lista dos maiores construtores brasileiros é publicada anualmente pela revista $O$ Empreiteiro. 


\section{QUADRO 2}

Participação de Construtores em

Concessões de Saneamento Básico

\begin{tabular}{|c|c|}
\hline \multicolumn{2}{|c|}{$\begin{array}{c}\text { CONCESSÕES DE SANEAMENTO - PLENAS } \\
\text { AMAZONAS }\end{array}$} \\
\hline Concessões realizadas & $\begin{array}{l}\text { Concessionárias com } \\
\text { presença de construtores }\end{array}$ \\
\hline 1 & \\
\hline \multicolumn{2}{|c|}{ ESPÍRITO SANTO } \\
\hline Concessões realizadas & $\begin{array}{l}\text { Concessionárias com } \\
\text { presença de construtores }\end{array}$ \\
\hline 1 & \\
\hline \multicolumn{2}{|c|}{ PARÁ } \\
\hline Concessões realizadas & $\begin{array}{l}\text { Concessionárias com } \\
\text { presença de construtores }\end{array}$ \\
\hline 1 & \\
\hline \multicolumn{2}{|c|}{ PARANÁ } \\
\hline $\begin{array}{c}\text { Concessões realizadas } \\
1\end{array}$ & $\begin{array}{c}\text { Concessionárias com } \\
\text { presença de construtores } \\
1\end{array}$ \\
\hline \multicolumn{2}{|c|}{ MATO GROSSO } \\
\hline Concessões realizadas & $\begin{array}{l}\text { Concessionárias com } \\
\text { presença de construtores }\end{array}$ \\
\hline 1 & 1 \\
\hline \multicolumn{2}{|c|}{ RIO DE JANEIRO } \\
\hline $\begin{array}{c}\text { Concessões realizadas } \\
6\end{array}$ & $\begin{array}{l}\text { Concessionárias com } \\
\text { presença de construtores } \\
5\end{array}$ \\
\hline \multicolumn{2}{|c|}{ SÃO PAULO } \\
\hline Concessões realizadas & $\begin{array}{l}\text { Concessionárias com } \\
\text { presença de construtores }\end{array}$ \\
\hline 5 & \\
\hline \multicolumn{2}{|c|}{$\begin{array}{c}\text { CONCESSÕES DE SANEAMENTO - ÁGUA } \\
\text { SÃO PAULO }\end{array}$} \\
\hline Concessões realizadas & $\begin{array}{l}\text { Concessionárias com } \\
\text { presença de construtores }\end{array}$ \\
\hline 5 & 3 \\
\hline \multicolumn{2}{|c|}{$\begin{array}{l}\text { CONCESSÕES DE SANEAMENTO - ESGOTO } \\
\text { SÃO PAULO }\end{array}$} \\
\hline Concessões realizadas & $\begin{array}{l}\text { Concessionárias com } \\
\text { presença de construtores }\end{array}$ \\
\hline 7 & 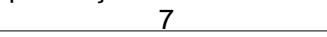 \\
\hline Concessões realizadas & $\begin{array}{l}\text { Concessionárias com } \\
\text { presenca de construtores }\end{array}$ \\
\hline 28 & 20 \\
\hline
\end{tabular}

Fonte: Página da Associação Brasileira das Concessionárias de Serviços Públicos de Água e Esgoto na Internet, janeiro de 2000. 
nas do serviço de esgoto. Construtores estão presentes em pelo menos vinte concessionárias $(71,42 \%)$ - isoladamente ou em consórcio com outras empresas ou grupos.

Trinta e quatro empresas ou grupos empresariais privados fazem parte das concessionárias de saneamento básico. Desse total, pelo menos vinte $(58,82 \%)$ são construtores.

TABELA 2: Construtores que Participam de Concessionárias de Saneamento Básico por Porte.

\begin{tabular}{cccccc}
\hline $\begin{array}{c}\text { Entre as 100 } \\
\text { maiores apenas } \\
\text { em 1992 }(\mathrm{a})\end{array}$ & $\begin{array}{c}\text { Entre as 100 } \\
\text { maiores apenas } \\
\text { em 1995 }(\mathrm{b})\end{array}$ & $\begin{array}{c}\text { Entre as 100 } \\
\text { maiores nas } \\
\text { duas listas }(\mathrm{c})\end{array}$ & $\begin{array}{c}(\mathrm{a})+(\mathrm{b}) \\
+(\mathrm{c})\end{array}$ & $\begin{array}{c}\text { Em nenhuma } \\
\text { das duas listas }\end{array}$ & TOTAL \\
\hline 0 & 02 & 08 & 10 & 10 & 20 \\
\hline
\end{tabular}

Fontes: Página da ABCON na Internet; Revista O Empreiteiro, junho de 1992 e julho de 1995.

A Tabela 2 revela que metade dos construtores que participam de concessionárias de saneamento básico estava entre os cem maiores construtores brasileiros em algum momento-chave da tramitação da legislação sobre concessões. A outra metade era de menor porte.

O Quadro 3 mostra a presença de construtores em concessionárias incumbidas de gerar ou distribuir energia elétrica.

Nenhum construtor participa das concessionárias que assumiram as geradoras de energia elétrica privatizadas. Por outro lado, construtores

QUADRO 3

Participação de Construtores em Concessionárias do Setor Elétrico

GERAÇÃO DE ENERGIA ELÉTRICA
Concessionárias com
presença de construtores
- APROVEITAMENTOS HIDRELÉTRICOS
CONCEDIDOS À INICIATIVA PRIVADA
Concessionárias com
presença de construtores
6

Fontes: BNDES (2000b) e página da ANEEL (Agência Nacional de Energia Elétrica) na Internet. 
estão presentes em seis das vinte concessionárias que assumiram aproveitamentos hidrelétricos concedidos à iniciativa privada (ou seja, 30\%) e em cinco das dezenove concessionárias que assumiram as distribuidoras de energia elétrica privatizadas (ou seja, 26,3\%).

No geral, cinqüenta e duas empresas ou grupos empresariais privados fazem parte das novas concessionárias do setor elétrico (BNDES, 2000a). Nove $(17,3 \%)$ são construtores.

A Tabela 3 mostra que sete construtores que participam de concessionárias do setor elétrico estavam entre os cem maiores construtores tanto em 1992 quanto em 1995. Apenas dois não estavam entre os cem maiores construtores brasileiros naquele período: a Construtora Impregilo e Associados e o Grupo Inepar. No entanto, é inadequado concluir que a participação desses dois construtores em concessionárias do setor elétrico evidencia a participação de construtores de menor porte. Embora não figure entre as maiores empresas do ramo de construção que atuam no Brasil, a Construtora Impregilo e Associados é ligada a Impregilo, uma grande construtora italiana. Por sua vez, o Grupo Inepar é um grande grupo empresarial brasileiro que atua em várias áreas, inclusive na construção. $\mathrm{O}$ grupo Inepar participa de concessionárias do setor elétrico como grande grupo empresarial - e não na condição de pequeno construtor.

TABELA 3: Construtores que Participam de Concessionárias do Setor Elétrico por Porte.

\begin{tabular}{cccccc}
\hline $\begin{array}{c}\text { Entre as 100 } \\
\text { maiores apenas } \\
\text { em 1992 (a) }\end{array}$ & $\begin{array}{c}\text { Entre as 100 } \\
\text { maiores apenas } \\
\text { em 1995 }(\mathrm{b})\end{array}$ & $\begin{array}{c}\text { Entre as 100 } \\
\text { maiores nas } \\
\text { duas listas }(\mathrm{c})\end{array}$ & $\begin{array}{c}(\mathrm{a})+(\mathrm{b}) \\
+(\mathrm{c})\end{array}$ & $\begin{array}{c}\text { Em nenhuma } \\
\text { das duas listas }\end{array}$ & TOTAL \\
\hline 0 & 0 & 07 & 07 & 02 & 09 \\
\hline
\end{tabular}

Fontes: BNDES (2000b); página da ANEEL na Internet; Revista O Empreiteiro, junho de $1992 \mathrm{e}$ julho de 1995.

O Quadro 4 informa sobre a presença de construtores em concessionárias incumbidas de prestar serviços de telefonia.

Foram realizadas, ao todo, vinte e sete concessões: nove de serviços de telefonia fixa, oito de serviços de telefonia móvel banda A e dez de serviços de telefonia móvel banda B. Construtores fazem parte pelo menos de oito concessionárias $(29,6 \%)$.

Quarenta e seis empresas ou grupos empresariais privados fazem parte das novas concessionárias de telefonia (BNDES, 2000b). Desse total, pelo menos cinco $(10,87 \%)$ são construtores.

8 Licitações realizadas até dezembro de 1998. 
QUADRO 4

Participação de Construtores em Concessões de Telefonia

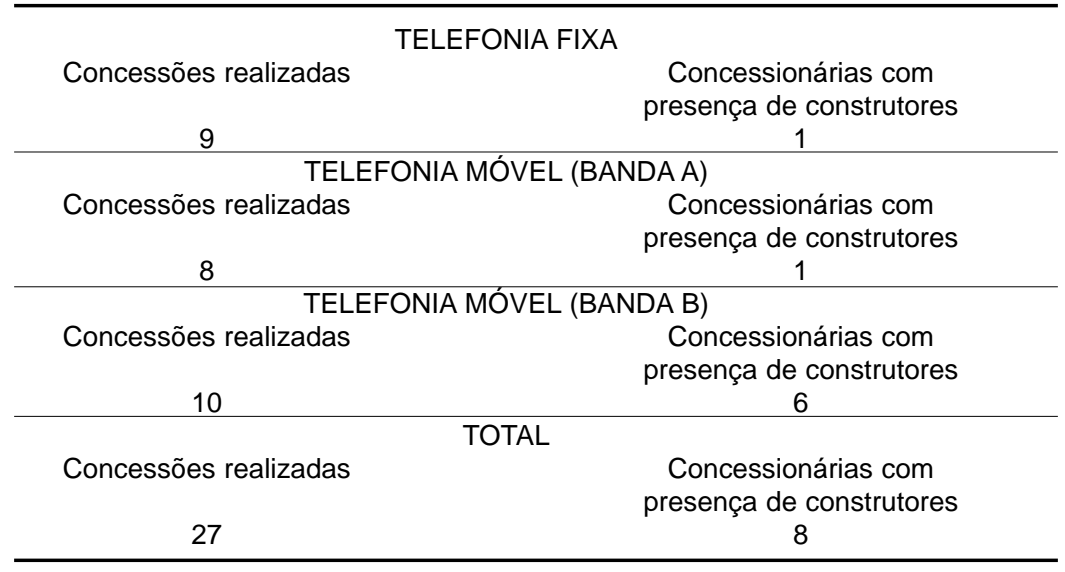

Fonte: BNDES (2000b).

A Tabela 4 mostra que, dentre os cinco construtores que fazem parte das novas concessionárias de telefonia, dois estavam entre os cem maiores construtores brasileiros em 1992 e em 1995. Três construtores não estavam entre os maiores construtores brasileiros em qualquer um dos dois momentos. Um deles é o Grupo Inepar, cuja participação em concessionárias de telefonia não evidencia a participação de construtores de menor porte em concessionárias desse setor. Outro é o Grupo Splice, cuja atividade se estende por áreas diversas, inclusive a construção. Pelas mesmas razões válidas para o caso do Grupo Inepar, é impróprio concluir que a participação do Grupo Splice em concessionárias de telefonia reflete a participação de construtores de menor porte nas concessionárias desse setor. $\mathrm{O}$ único construtor de menor porte a participar das concessões no setor de telefonia foi a Alusa Engenharia, associada da Associação Paulista dos Empresários de Obras Públicas (APEOP).

TABELA 4: Construtores que Participam de Concessionárias de Telefonia por Porte

\begin{tabular}{cccccc}
\hline $\begin{array}{c}\text { Entre as 100 } \\
\text { maiores apenas } \\
\text { em 1992 (a) }\end{array}$ & $\begin{array}{c}\text { Entre as 100 } \\
\text { maiores apenas } \\
\text { em 1995 (b) }\end{array}$ & $\begin{array}{c}\text { Entre as 100 } \\
\text { maiores nas } \\
\text { duas listas }(\mathrm{c})\end{array}$ & $\begin{array}{c}(\mathrm{a})+(\mathrm{b}) \\
+(\mathrm{c})\end{array}$ & $\begin{array}{c}\text { Em nenhuma } \\
\text { das duas listas }\end{array}$ & TOTAL \\
\hline 0 & 0 & 02 & 02 & 03 & 05 \\
\hline
\end{tabular}

Fontes: BNDES (2000b); Revista O Empreiteiro, junho de 1992 e julho de 1995. 
O Quadro 5 informa sobre a presença de construtores nas concessionárias de malhas ferroviárias.

QUADRO 5

Participação de Construtores em

Concessões de Ferrovias

\begin{tabular}{cc}
\hline Concessões realizadas & Concessionárias com \\
8 & presença de construtores \\
8 & 3 \\
\hline
\end{tabular}

Fontes: BNDES (1999) e página da RFFSA na Internet.

Oito malhas ferroviárias foram concedidas e construtores fazem parte de três consórcios concessionários. Trinta e cinco empresas fazem parte dos consórcios (BNDES 1999), dentre as quais há apenas duas $(5,71 \%)$ construtoras. Uma estava entre as cem maiores do Brasil tanto em 1992 quanto em 1995, a outra não estava. Mas a construtora que não figurava entre as maiores do país em 1992 e em 1995 é a Gemon Geral de Engenharia e Montagens, do Grupo MPE, um grande grupo empresarial brasileiro que atua em áreas diversas. Pelas mesmas razões válidas para os casos considerados acima, não é apropriado concluir que a participação da Gemon Geral em concessões ferroviárias representa a participação de construtores de menor porte em concessões desse setor.

Finalmente, o Quadro 6 mostra a participação de empresas ou grupos construtores em concessionárias que prestam serviço de distribuição de gás canalizado.

\section{QUADRO 6 \\ Participação de Construtores em Concessões de Distribuição de Gás}

\begin{tabular}{ccc}
\hline Empresas leiloadas & RIO DE JANEIRO & $\begin{array}{c}\text { Concessionárias com } \\
\text { presença de construtores } \\
2\end{array}$ \\
\hline Empresas leiloadas & SÃO PAULO & $\begin{array}{c}\text { Concessionárias com } \\
\text { presença de construtores } \\
1\end{array}$ \\
3 & & \\
\hline
\end{tabular}

Fonte: BNDES (1998)

Foram realizadas cinco concessões. Onze empresas fazem parte dos consórcios concessionários (BNDES, 2000b). Em um consórcio há a participação de um grupo construtor. Esse grupo construtor figurava entre os cem maiores construtores brasileiros tanto em 1992 quanto em 1995. 
Em resumo, o conjunto dos dados apresentados nesta seção mostra que os construtores estão presentes em concessionárias responsáveis pela prestação de todos os seis tipos de serviços públicos considerados. A presença de construtores - tanto dos que figuravam entre os maiores do Brasil em algum momento-chave da tramitação da legislação sobre concessões quanto dos que não figuravam - é maior nas concessionárias de estradas, mas também é muito significativa nas concessionárias de saneamento básico. Por outro lado, a presença de construtores em concessionárias do setor elétrico, de telefonia, de ferrovias e de gás canalizado é tímida e quase totalmente restrita a empresas que a) figuravam entre as maiores do país em algum momento-chave da tramitação da legislação sobre concessões ou que b) atuam na construção, não figuravam entre as maiores do país, mas fazem parte de grupos empresariais de grande porte.

\section{AS ENTIDADES E A ELABORAÇÃO DAS LEIS}

A expressiva maioria das entidades que representam os interesses dos construtores é formada por sindicatos patronais de base municipal, estadual ou nacional. Segundo a CNI - entidade de cúpula do setor industrial no Brasil - há sessenta e três sindicatos patronais da indústria da construção distribuídos pelo país ${ }^{9}$.

O papel que os sindicatos desempenham na estrutura de representação dos interesses dos construtores é dominante mas não é exclusivo. O quadro das organizações que intermedeiam os interesses dos construtores é complementado pelas associações setoriais extracorporativas. Desse modo, também foram contatadas as quatro principais associações do setor, cuja importância é amplamente reconhecida: a Associação das Construtoras de Centrais Energéticas (ACCE), a Associação Nacional das Empresas de Obras Rodoviárias (ANEOR), a Associação Paulista de Empresários de Obras Públicas (APEOP) e a Câmara Brasileira da Indústria da Construção (CBIC).

Ao todo, portanto, foram contatadas sessenta e sete entidades. Em cada caso indivíduos que ocupavam posições de liderança no organograma das organizações foram interpelados sobre o grau de envolvimento das entidades ao longo do processo de feitura da legislação que rege as con-

\footnotetext{
${ }^{9}$ A lista dos sindicatos foi fornecida pela Gerência de Relações de Trabalho da Confederação Nacional da Indústria. Não são considerados os sindicatos da indústria de construção de mobiliário.
} 
cessões de serviço público no Brasil. O envolvimento de uma entidade no processo de feitura da lei das concessões seria pouco provável se ela não possuísse ao menos algum grau de informação sobre o projeto que estava em tramitação e se sua diretoria não partilhasse do entendimento de que as concessões poderiam ampliar o campo de atuação das empresas filiadas. Dessa forma, lideranças de cada entidade foram solicitadas a responder duas perguntas. A primeira pergunta referia-se ao nível de informação que a diretoria da entidade possuía a respeito do projeto de lei geral das concessões no período anterior à sanção da lei. A segunda pergunta referia-se à opinião da diretoria em relação à capacidade das concessões de serviços públicos de gerar oportunidades de negócios para os construtores filiados.

TABELA 5: Informação sobre o Projeto de Lei Geral das Concessões e Ponto de Vista sobre as Concessões.

\begin{tabular}{|c|c|c|c|}
\hline & $\begin{array}{l}\text { Entidades com diretorias } \\
\text { informadas }\end{array}$ & $\begin{array}{l}\text { Entidades sem diretorias } \\
\text { informadas }\end{array}$ & TOTAL \\
\hline $\begin{array}{l}\text { Entidades que vêem as } \\
\text { concessões como } \\
\text { mercado potencial para } \\
\text { filiados }\end{array}$ & 22 & 8 & 30 \\
\hline $\begin{array}{l}\text { Entidades que não vêem } \\
\text { as concessões como } \\
\text { mercado potencial para } \\
\text { filiados }\end{array}$ & 4 & 5 & 9 \\
\hline TOTAL & 26 & 13 & 39 \\
\hline
\end{tabular}

Fontes: Questionários respondidos pelas entidades; entrevistas com diretores de entidades.

A Tabela 5 emerge das respostas apresentadas pelas entidades ${ }^{10}$. Das sessenta e sete entidades contatadas, trinta e nove $(58,2 \%)$ responderam as questões que lhes foram apresentadas. Dentre as trinta e nove entidades respondentes, vinte e duas $(56,41 \%)$ possuíam diretorias a) pelo menos um pouco informadas sobre o projeto de lei geral das concessões e b) com a opinião de que as concessões geram oportunidades de negócios pelo menos para algumas empresas filiadas às suas entidades. Ou seja: vinte e duas entidades possuíam os requisitos mínimos sem os quais dificilmente uma entidade poderia participar do processo de elaboração da lei das concessões.

10 O questionário enviado pode ser solicitado pelo e-mail: pralon@usp.br . 
No entanto, dentre essas vinte e duas entidades, apenas duas apresentaram evidências inequívocas de participação na feitura da legislação sobre concessões: a Associação das Construtoras de Centrais Energéticas (ACCE) e o Sindicato da Indústria da Construção Civil de Grandes Estruturas do Estado de São Paulo (SINDUSCON/SP).

\section{A PARTICIPAÇÃO DA ACCE}

A Associação das Construtoras de Centrais Energéticas existiu por um período de oito anos, entre fevereiro de 1990 e fevereiro de 1998. A ACCE possuía apenas doze empresas filiadas, todas elas empresas construtoras de grande porte: Andrade Gutierrez, Camargo Corrêa, CBPO, CONSTRAN, CONVAP, COWAN, C. R. Almeida, Mendes Júnior, Norberto Odebrecht, Queiroz Galvão, Serveng-Civilsan e TRATEX (ACCE 1990). Todas as empresas construtoras filiadas à ACCE figuravam na relação das vinte e cinco maiores construtoras brasileiras no início da década de $1990^{11}$. A ACCE foi criada para negociar uma solução para o problema da dívida que o governo brasileiro havia constituído com as grandes construtoras que haviam sido contratadas para construir as principais centrais energéticas do país.

A ACCE foi a entidade que centralizou a participação dos grandes construtores no processo de elaboração da legislação brasileira sobre concessões de serviços públicos. Sua atuação ocorreu em diversos estágios do processo de produção legislativa.

A ACCE realizou um extenso trabalho de pressão em maio de 1992, enquanto o projeto de lei das concessões estava sendo analisado na comissão de economia, indústria e comércio da Câmara dos Deputados (CEIC/CD). A entidade apresentou várias sugestões ao relator do projeto de lei na comissão, enquanto ele preparava um projeto substitutivo ao projeto original apresentado pelo senador Fernando Henrique Cardoso (PSDB/SP). Nesse momento, as sugestões da ACCE concentraram-se em torno de quatro pontos (ACCE 1994a). Em primeiro lugar, a entidade queria alterar os trechos da minuta do substitutivo que estipulavam limites de prazo para as concessões (30 anos) e para a prorrogação das concessões (um único período adicional de 20 anos). No que diz respeito ao prazo inicial das concessões, a entidade defendia a idéia de que ele pudesse ser fixado em cada

${ }^{11}$ Revista O Empreiteiro, junho de 1992. 
edital de licitação, guardando proporção com o vulto de cada empreendimento, a fim de que pudesse assegurar amortização plena do capital investido e possibilidades de lucro razoável às concessionárias. No que se refere ao prazo máximo da concessão (prazo inicial mais prorrogação), a ACCE defendia o limite de 90 anos em vez de 50 anos. Em segundo lugar, a ACCE queria suprimir o trecho da minuta do substitutivo que estabelecia que eventuais aumentos das alíquotas do imposto de renda não poderiam implicar no aumento das tarifas cobradas pelas concessionárias. Em terceiro lugar, a ACCE queria definir claramente no substitutivo que o poder concedente - $\mathrm{e}$ nunca as concessionárias - seria o único responsável por indenizações referentes às desapropriações necessárias para viabilizar a prestação dos serviços públicos e/ou a realização de obras que antecedessem a prestação dos serviços. Em quarto lugar, a entidade queria introduzir no substitutivo um dispositivo que autorizasse as concessionárias a oferecer quaisquer direitos emergentes dos seus contratos de concessão como garantia nos contratos de financiamentos que viessem a celebrar.

Duas sugestões defendidas pela ACCE foram incorporadas ao substitutivo que o relator apresentou em seguida. Por um lado, foi retirada qualquer menção a um limite para o prazo inicial das concessões. Por outro lado, as concessionárias foram autorizadas a oferecer quaisquer direitos emergentes dos contratos de concessão como garantias em contratos de financiamento, até o limite que não comprometesse a operacionalização e a continuidade da prestação do serviço. A adoção dessas medidas foi celebrada pela entidade de construtores como um resultado direto da sua intervenção (ACCE 1995a) ${ }^{12}$.

A ACCE voltou a desempenhar intensa atividade de pressão política em dezembro de 1994, às vésperas da votação da lei geral das concessões no Senado Federal. Nesse momento a entidade defendeu principalmente três alterações no projeto de lei (ACCE 1994b). Em primeiro lugar, a entidade defendeu o restabelecimento de um artigo do projeto original do senador Fernando Henrique Cardoso, artigo que relacionava todos os fatores de custo a serem levados em conta para a fixação das tarifas a

\footnotetext{
12 Este artigo não aborda a questão complexa e controvertida da influência efetivamente exercida pelos grupos de interesse em processos de tomada de decisão. É necessário sempre levar em conta que os líderes dos grupos de interesse podem superestimar estrategicamente sua capacidade de influência. Dentre os trabalhos que tratam da questão estão March (1956), Dahl (1959), Milbrath (1960), Schmitter (1971), Wootton (1972), Salisbury (1975), Salamon \& Siegfried (1977), Tierney (1992), Smith (1995), Evans (1996), Potters \& Sloof (1996) e Furlong (1997).
} 
serem cobradas pelas concessionárias privadas de serviços públicos. A especificação minuciosa dos fatores de custo era vista como uma medida essencial para a segurança das concessionárias. $\mathrm{O}$ artigo havia sido derrubado pelo substitutivo aprovado pela Câmara dos Deputados. Essa sugestão da ACCE claramente não foi aceita, porquanto nenhuma alteração desse teor foi introduzida no texto aprovado pelo Senado Federal. Em segundo lugar, a entidade sugeriu o restabelecimento de outro artigo do projeto do senador Cardoso, artigo que permitia que o poder concedente garantisse às concessionárias, durante o primeiro terço do prazo da concessão, o recebimento de um valor equivalente a uma receita bruta mínima, valor a ser pago caso a demanda pelos serviços das concessionárias não fosse suficiente para que elas obtivessem uma tal receita. O dispositivo em questão foi restabelecido e passou a constar no texto aprovado pelo Senado Federal e enviado à sanção presidencial. Para a ACCE o restabelecimento do dispositivo ocorreu em função da pressão política por ela exercida sobre os senadores (ACCE 1995b). O presidente da República Fernando Henrique Cardoso, no entanto, vetou o artigo do projeto de lei aprovado no Senado, artigo que ele mesmo havia proposto quando senador. Para Cardoso, o oferecimento de tais garantias deveria ser coibido por incentivar a ineficiência do concessionário e por criar riscos de dispêndio com subsídios para o poder público ${ }^{13}$. Em terceiro lugar, a ACCE propôs a supressão dos dispositivos referentes às concessões de serviços públicos outorgadas antes da vigência da nova lei e que estavam vencidas, por vencer em curto prazo, ou em vigor por prazo indeterminado. $\mathrm{O}$ sentido e o resultado dessa intervenção da ACCE é apresentado em seguida.

A ACCE tornou a manifestar-se em fevereiro de 1995. Dessa vez o foco de pressão da entidade não foi posto sobre o poder legislativo, mas sobre o poder executivo. A entidade queria influenciar o conteúdo da medida provisória (MP) que o governo federal prometeu editar no mesmo dia em que a lei geral das concessões fosse sancionada. $\mathrm{O}$ governo federal prometeu dar solução, por meio de uma MP, para os problemas do setor elétrico que estavam inviabilizando a votação da lei geral das concessões no Senado Federal. De fato, é oportuno lembrar que o grande empecilho à votação da lei geral das concessões no Senado Federal eram os dispositivos do substitutivo aprovado pela Câmara que dispunham exatamente sobre as concessões de serviço público outorgadas antes da entrada em vigor da nova lei de concessões. Esses dispositivos estabeleciam que a) as con-

13 Diário Oficial da União, Seção I, 14/02/1995, página 1922. 
cessões outorgadas anteriormente à entrada em vigor da nova lei permaneceriam válidas pelo prazo fixado no contrato ou no ato de outorga, findo o qual seriam licitadas; b) as concessões em caráter precário (ou seja, as que não dependiam de contrato), as concessões com prazo vencido e as concessões em vigor por prazo indeterminado deveriam permanecer válidas pelo prazo mínimo de dois anos e pelo prazo máximo de cinco anos, prazo no qual deveria ser feita a organização das licitações que precederam as nova concessões e c) as concessões outorgadas sem licitação na vigência da Constituição de 1988 deveriam ser extintas, assim como aquelas outorgadas sem licitação anteriormente à Constituição de 1988 e que estivessem paradas ou sequer iniciadas.

Esses dispositivos do substitutivo da Câmara dos Deputados traziam problemas para o setor elétrico nacional, especificamente para as concessionárias estaduais de energia elétrica, muitas delas detentoras de concessões vencidas, por vencer em curto prazo ou em vigor por prazo indeterminado. De acordo com o substitutivo da Câmara, várias dessas concessões deveriam ser licitadas dentro do prazo máximo de cinco anos.

Para contornar o impasse, o governo federal comprometeu-se a editar uma medida provisória que teria por objetivo disciplinar a aplicação da lei das concessões ao setor elétrico. A medida provisória seria editada no mesmo dia em que o presidente da república sancionasse a lei geral das concessões. No que se refere à geração de energia elétrica, o governo federal iria assumir dois compromissos: a) permitir a prorrogação das concessões das usinas em operação pelo prazo de até vinte anos e b) permitir a prorrogação das concessões cujas obras estivessem atrasadas ou paralisadas pelo prazo necessário à amortização do capital investido, nos casos em que houvesse sociedade do setor público com o setor privado e um plano viável para a conclusão das obras em ritmo adequado. No que se refere à transmissão de energia elétrica, o governo federal iria tomar as seguintes providências: a) permitir a prorrogação e/ou o reagrupamento das autorizações e concessões e b) criar um sistema de transmissão de energia elétrica com livre acesso para os interessados. No que se refere à distribuição de energia elétrica, o governo iria permitir a prorrogação e/ou o reagrupamento das concessões de distribuição. Nos casos em que a privatização total ou parcial das concessionárias estaduais de energia elétrica interessasse aos estados, o governo federal se comprometeria a prorrogar concessões já outorgadas ou a estabelecer novas concessões para facilitar e valorizar a alienação, desde que esta fosse realizada mediante leilão ou concorrência. 
O compromisso assumido pelo governo viabilizou a votação e a aprovação da lei geral das concessões de serviços públicos no senado $\mathrm{Fe}$ deral em janeiro de 1995. No mesmo dia em que o presidente Sancionou a lei geral das concessões - 13 de fevereiro de 1995 - ele também editou a Medida Provisória ${ }^{\circ} 890$.

A ACCE teve rápido acesso à minuta da MP. Vinte dias após a votação da lei das concessões no senado federal, ou seja, em 07 de fevereiro de 1995, a presidência da entidade fez chegar ao Secretário de Energia do Ministério de Minas e Energia um comunicado de apoio à minuta, especialmente aos pontos em que se previa a prorrogação das concessões de geração de energia elétrica. Não é difícil imaginar porque a prorrogação das concessões de geração de energia elétrica interessava às grandes construtoras. A prorrogação das concessões das geradoras que já estavam em operação era do interesse das grandes empresas construtoras porque aquelas geradoras poderiam vir a ser privatizadas. A privatização das geradoras com concessões prorrogadas poderia gerar oportunidades de negócios diretas (caso as construtoras quisessem tornar-se concessionárias) e indiretas (as construtoras poderiam oferecer seus serviços especializados às novas concessionárias). É plausível supor que também interessava às construtoras a prorrogação das concessões de geração de energia elétrica cujos empreendimentos estivessem atrasados ou paralisados. Essas concessões também poderiam gerar novas oportunidades de negócios, diretas (caso as construtoras quisessem fazer parte de consórcios incumbidos de concluir as obras e colocar as geradoras em operação) ou indiretas.

Finalmente, as atividades de pressão da ACCE também ocorreram ao longo do período em que uma comissão mista do Congresso Nacional analisou a MP das concessões. A ACCE foi a única entidade do setor da construção convidada para participar de uma audiência pública no Congresso Nacional para discutir aquela MP. As sugestões oferecidas pelo representante da ACCE nessa oportunidade concentravam-se em torno de quatro pontos ${ }^{14}$ : a) em primeiro lugar, a introdução de um artigo para regulamentar a indenização devida às concessionárias ao término do contrato de concessão. A indenização deveria contemplar não apenas o capital investido pelas concessionárias e ainda não amortizado, mas também a remuneração desse capital investido para assegurar a continuidade da prestação do serviço concedido; b) em segundo lugar, a introdução de um artigo com

14 Notas Taquigráficas da Audiência Pública n 52/95 (Núcleo de Revisão de Comissões; Departamento de Taquigrafia, Revisão e Redação da Câmara dos Deputados); ACCE (1995c). 
critérios objetivos a serem seguidos pelo poder concedente para classificar a proposta oferecida por um participante de uma licitação como uma proposta inexequíivel ou financeiramente incompatível com os objetivos da licitação; c) em terceiro lugar, a introdução de um artigo condicionando o cumprimento das condições estabelecidas no contrato de concessão à não ocorrência de circunstâncias de mercado ou outras circunstâncias fora do controle das partes e que fossem capazes de comprometer o equilíbrio econômico e financeiro inicial do contrato e d) em quarto lugar, a introdução de um artigo para esclarecer que não deveria ocorrer a reversão ao poder concedente dos bens de empresas estatais concessionárias de serviços públicos que fossem privatizadas e cujos novos donos recebessem novas concessões. Nesses casos, deveria ser viabilizado o repasse direto dos bens das antigas concessionárias para as novas concessionárias. Nenhuma sugestão foi totalmente incorporada à Lei $\mathrm{n}^{\circ}$ 9074, de julho de 1995 , que resultou da MP das concessões. Todavia, há semelhanças entre a última sugestão da ACCE e o disposto no artigo 28 da lei $n^{\circ} 9074$. Este artigo faculta (mas não obriga) ao poder concedente, em casos de privatização, a outorga de novas concessões aos novos concessionários sem efetuar a reversão prévia dos bens vinculados ao respectivo serviço público.

Em síntese, as informações apresentadas anteriormente indicam que a ACCE, uma entidade que representava os interesses dos grandes construtores brasileiros, teve uma participação extremamente ativa durante os vários estágios que compuseram o processo de feitura da legislação que atualmente rege as concessões de serviços públicos no Brasil. A ACCE exerceu pressão política quando o projeto de lei geral das concessões estava numa comissão temática da Câmara dos Deputados e quando o mesmo projeto se encontrava no plenário do Senado Federal. A ACCE também exerceu pressão ao longo do processo que culminou com a aprovação da lei $n^{\circ} 9074$, que complementou a lei geral das concessões. Nesse caso, a participação da entidade remonta ao momento em que a medida provisória N. 890 estava sendo redigida pelo poder executivo. Além disso, a pressão da entidade também se fez sentir durante uma audiência pública convocada para discutir a MP das concessões, audiência para a qual a ACCE foi formalmente convidada.

\section{A PARTICIPAÇÃO DO SINDUSCON/SP}

Ao contrário da ACCE, o Sindicato da Indústria da Construção Civil de Grandes Estruturas do Estado de São Paulo (SINDUSCON/SP) é 
uma entidade quase totalmente composta por empresas que não figuravam entre as maiores construtoras brasileiras durante a tramitação da legislação sobre concessões (SINDUSCON/SP 1998). Das mil, quinhentas e seis empresas que estavam associadas ao SINDUSCON/SP em 1998, apenas vinte e oito (1,85\%) figuravam entre as cem maiores construtoras brasileiras em 1992 e apenas trinta e seis (2,4\%) figuravam entre as cem maiores construtoras brasileiras em 1995.

A participação do SINDUSCON/SP no processo de produção da legislação sobre concessões foi bem mais restrita do que a da ACCE. Todo o empenho do SINDUSCON/SP foi concentrado em torno de uma questão: garantir que as linhas de financiamento do BNDES para empresas concessionárias de serviços públicos não ficassem disponíveis apenas para as empresas de grande porte. De fato, um dispositivo do projeto aprovado pelo Senado Federal e remetido à sanção presidencial dispunha que o BNDES deveria exigir garantias adicionais, para além dos direitos emergentes das concessões, quando fosse conceder financiamentos às empresas concessionárias. Na visão do SINDUSCON/SP, esse dispositivo representava uma discriminação inaceitável contra as empresas de porte pequeno e médio e em favor das empresas de porte grande, as únicas que teriam condições de apresentar ao BNDES as garantias adicionais exigida pela lei. O objetivo do SINDUSCON/SP, portanto, era garantir que o presidente da República vetasse o dispositivo que contrariava os interesses das empresas de porte menor. Tendo em vista esse objetivo, a entidade desenvolveu diversas ações. Em primeiro lugar, o presidente da entidade enviou uma carta ao ministro-chefe da Casa Civil pedindo o veto presidencial do dispositivo citado. Em segundo lugar, o sindicato coordenou uma campanha de mobilização pelo veto entre os seus associados, incentivando-os a entrar em contato, de todas as maneiras possíveis, com a Presidência da República (SINDUSCON 1995). Em terceiro lugar, o presidente da entidade publicou um artigo no jornal Folha de S. Paulo no qual expunha as razões pelas quais defendia o veto do dispositivo ${ }^{15}$.

$\mathrm{O}$ presidente Fernando Henrique Cardoso não realizou o veto solicitado pelo presidente do SINDUSCON/SP ao sancionar a lei geral das concessões. No entanto, o artigo 40 da lei $\mathrm{n}^{\circ}$ 9074, publicada cerca de cinco meses depois, terminou por revogar o dispositivo criticado pela entidade.

15 Folha de S. Paulo, 08 de fevereiro de 1995, Caderno 2, Página 2. 


\section{CONSIDERAÇÕES FINAIS}

A análise do comportamento assumido pelas entidades que representam os interesses dos construtores durante o processo de elaboração da legislação sobre concessões de serviços públicos no Brasil sugere que realmente ocorreram os dois fenômenos previstos pela teoria olsoniana da ação coletiva: a carona e a exploração do grande pelo pequeno.

Entidades com bons motivos para participar do processo de elaboração da legislação sobre concessões parecem ter deixado para a ACCE uma entidade que congregava poucos construtores de porte muito grande, para os quais as oportunidades geradas pelas concessões eram maiores do que as geradas para os construtores de porte menor - quase todo o custo da obtenção do bem coletivo: a segurança proporcionada por uma "boa" legislação sobre concessões.

Quando o que estava em jogo não era a definição de regras gerais que poderiam dar segurança a quaisquer concessionários em potencial, mas o destino de um dispositivo específico que criava um conflito de interesses entre as empresas construtoras em função do porte de cada uma delas, a entidade que concentrou os esforços de pressão foi o SINDUSCON/SP, que coordenou o lobby para garantir que as linhas de financiamento do BNDES para empresas concessionárias de serviços públicos não ficassem disponíveis apenas para os grandes construtores. Embora o veto do dispositivo pudesse beneficiar as empresas filiadas a várias entidades da construção, apenas o SINDUSCON/SP mobilizou-se por ele, de acordo com as informações disponíveis.

Este artigo focaliza uma parcela específica do empresariado brasileiro (a indústria da construção) e sua atuação no processo de elaboração de regras também específicas (a legislação sobre concessões de serviços públicos), mas ele oferece uma contribuição para o estudo de uma questão de importância mais geral, que diz respeito a articulação dos interesses do empresariado que atua no Brasil ao longo do processo de produção legislativa de nível federal.

Não obstante as dificuldades ligadas ao caráter fugidio da articulação de interesses e à escassez de informações confiáveis, os cientistas políticos brasileiros vêm dando atenção ao tema já há algum tempo (Aragão 1994, 1996, 2000; Diniz \& Boschi 1997, 2000). A contribuição oferecida por este artigo segue esses trabalhos pioneiros, cujos autores foram os primeiros a apontar para o fato de que a redemocratização do Brasil, a partir de meados da década de 1980, resultou no incremento das 
prerrogativas e da relevância política do Congresso Nacional, atraindo para esse novo fórum a atuação de vários grupos de interesse - entre eles os do empresariado.

O artigo mostra que a articulação dos interesses empresariais é uma atividade que ocorre durante os diversos estágios do processo de produção legislativa. A articulação pode remontar até mesmo ao estágio de redação inicial de uma proposição. Ela pode ocorrer também no estágio de discussão dos projetos nas duas Casas do Congresso Nacional, no estágio de análise e votação dos projetos nas comissões ou no plenário ou ainda no estágio da sanção (ou veto) presidencial.

$\mathrm{O}$ artigo mostra ainda que a pressão política em defesa dos interesses do empresariado é exercida algumas vezes "por dentro" do processo de produção legislativa, o que ocorre quando os tomadores de decisão convidam oficialmente as entidades que representam os interesses das empresas para participar de audiências públicas ou reuniões de trabalho e para apresentar sua posição em relação a um assunto ou a uma proposição. Muitas vezes, no entanto, a pressão política é realizada "por fora" do processo normal de produção legislativa, casos em que os contatos de negociação com os tomadores de decisão não ocorrem em encontros oficiais e em que a iniciativa é tomada, na maior parte das vezes, pelos próprios representantes do empresariado.

Além disso, o artigo também indica que o empresariado brasileiro, ao procurar influir no processo de produção legislativa, leva em conta o papel de destaque que é desempenhado pelo Poder Executivo durante aquele processo. Os indivíduos que ocupam posições de autoridade no Poder Executivo são interlocutores privilegiados do empresariado no que diz respeito à promoção da agenda desse segmento social no Congresso Nacional. A importância do Executivo deve ser vista como um dos elementos que formam o ambiente com que os representantes dos empresários tem de lidar e que, portanto, condicionam as suas decisões e estratégias de articulação de interesses. $\mathrm{O}$ artigo sugere que a aprovação pelo congresso de proposições oriundas do Executivo muitas vezes é o resultado final de um processo de negociação no qual estão fortemente envolvidos os interesses dos grupos sociais afetados - dentre os quais freqüentemente se encontra o empresariado. Além disso, a atuação das entidades empresariais no que se refere às proposições legislativas de autoria do Poder Executivo pode se fazer sentir em estágios muito precoces, que remontam até mesmo ao momento da formulação daquelas proposições nas instâncias do Executivo. Algumas proposições de autoria do Poder Executivo aprovadas pelo 
Congresso Nacional até mesmo nascem como uma resposta política encontrada pelo governo e por sua base de apoio no Parlamento para contornar impasses criados pela oposição de interesses fortemente representados no Congresso, impasses que poderiam obstar o avanço de projetos que fazem parte da agenda política do Governo Federal. Em síntese, o artigo contribui para o entendimento de que a atuação e a influência dos interesses organizados não estão excluídas nem mesmo em um cenário marcado pela preponderância do Poder Executivo na produção legislativa (Figueiredo \& Limongi 2000).

A ciência política no Brasil teria muito a ganhar se mais pesquisadores concedessem o status de objeto privilegiado de investigação ao terreno fertilíssimo e relativamente inexplorado formado pelos casos de apresentação das demandas do empresariado aos tomadores de decisões políticas.

WAGNER PRALON MANCUSO é doutorando em Ciência Política na USP.

\section{REFERÊNCIAS BIBLIOGRÁFICAS}

ARAGÃO, Murillo de (1994). Grupos de pressão no Congresso Nacional: como a sociedade pode defender licitamente seus direitos no Poder Legislativo. São Paulo. Maltese.

ARAGÃO, Murillo de (1996). "A ação dos grupos de pressão nos processos constitucionais recentes no Brasil". Revista de Sociologia e Política, n.os 6/7, Universidade Federal do Paraná, Curitiba, PR.

ARAGÃO, Murillo de (2000). "Brasil e Argentina: abordagem comparada sobre grupos de pressão no Poder Legislativo". Tese de Doutorado, Centro de Pesquisa e PósGraduação sobre a América Latina e Caribe, Universidade de Brasília.

DAHL, RobertA. (1959)- "Business and Politics: ACritical Appraisal of Political Science”. American Political Science Review, vol. 53, n.o 1.

DINIZ, Eli; BOSCHI, Renato (1997). "O Legislativo como arena de interesses organizados: a atuação dos lobbies empresariais. (Artigo não publicado).

DINIZ, Eli; BOSCHI, Renato (2000). "Globalização, herança corporativa e a representação dos interesses empresariais: novas configurações no cenário pós-reformas" in: BOSCHI, Renato (org.). Elites políticas e econômicas no Brasil contemporâneo: a desconstrução da ordem corporativa e o papel do Legislativo no cenário pósreformas. Fundação Konrad Adenauer.

EVANS, Diana (1996). "Before the Roll Call: Interest Group Lobbying and Public Policy Outcomes in House Committees". Political Research Quarterly, vol. 49, n.o 2.

FIGUEIREDO, Argelina \& LIMONGI, Fernando (2000). "Presidential Power, Legislative Organization, and Party Behavior in Brazil". Comparative Politics, vol. 32, n.o. 2.

FURLONG, Scott R. (1997). "Interest Group Influence on Rule Making". Administration \& Society, vol. 29, n.o 3.

MANCUSO, Wagner Pralon (2000). “A Indústria da Construção e a Legislação sobre 
Concessões de Serviços Públicos". Dissertação de Mestrado apresentada ao Departamento de Ciência Política da Universidade de São Paulo.

MARCH, James (1956). "An Introduction to the Theory and Measurement of Influence" in: Eulau, Heinz (org.) Political Behavior: A Reader in Theory and Research. Free Press, Glencoe, Ill.

MILBRATH, Lester W. (1960) - "Lobbying as a Communication Process". Public Opinion Quarterly, vol. 24, n.o. 1.

MOE, Terry M. (1988). The Organization of Interests. University of Chicago Press.

OLSON, Mancur (1999). A Lógica da Ação Coletiva. São Paulo, Edusp.

OLSON, Mancur \& ZECKHAUSER, Richard (1966). "An Economic Theory of Alliances". Review of Economics and Statistics, n.o 48.

POTTERS, Jan \& SLOOF, Randolph (1996). "Interest Groups: A Survey of Empirical Models that try to Assess their Influence”. European Journal of Political Economy, vol. 12.

SALAMON, Lester \& SIEGFRIED, John (1977). "Economic Power and Political Influence: The Impact of Industry Structure on Public Policy". American Political Science Review, vol. 71, n.o 3 .

SALISBURY, Robert (1975). "Interest Groups" in: Polsby, N. \& Greenstein, F. (eds.) Handbook of Political Science, vol. 4. Addison-Wesley.

SCHMITTER, Philippe C. (1971) Interest Conflict and Political Change in Brazil. Stanford University Press.

SMITH, Richard A. (1995). "Interest Group Influence in the U.S. Congress". Legislative Studies Quarterly, vol. 20, n.o 1.

TIERNEY, John (1992). “Organized Interests and Nation's Capital”. in: Petracca, Mark (org.). The Politics of Interests: Interest Groups Transformed. Boulder, Colorado. Westview Press.

WOOTTON, Graham (1972). Grupos de Interesse. Rio de Janeiro, Zahar.

\section{Jornais e Revistas}

Folha de S. Paulo, 08 de fevereiro de 1995, Caderno 2, Página 2.

Revista $O$ Empreiteiro, junho de 1992. Editora Univers.

Revista $O$ Empreiteiro, julho de 1995. Editora Univers.

\section{Diários Oficiais}

Diário Oficial da União, Seção I, 14/02/1995, página 1922.

\section{Publicações de Entidades}

ACCE (1990). Boletim Informativo ACCE em Pauta, Suplemento Especial, Ano I, Número I, Dezembro.

ACCE (1994a). "Emendas preparadas por comissão da ACCE em Maio de 1992" in: A ACCE e a Lei das Concessões.

ACCE (1994b). Boletim Informativo ACCE em Ação. N.o 6, 29 de dezembro.

ACCE (1995a). Boletim Informativo ACCE em Ação, N.o 8, 24 de janeiro.

ACCE (1995b). Boletim Informativo ACCE em Ação. N.o 10, 06 de março.

ACCE (1995c). "Sugestões relativas à MP", n.o. 890, de 13 de fevereiro de 1995, volume 3.

BNDES (1998) Privatization in Brazil: 1991-1998 - Secretaria Geral de Apoio à Desestatização do Banco Nacional de Desenvolvimento Econômico e Social.

BNDES (1999). Sistema de Informações de 31 de dezembro de 1998. Secretaria Geral de Apoio à Desestatização do Banco Nacional de Desenvolvimento Econômico e Social

BNDES (2000a). Leilões de Concessão de Energia Elétrica - Secretaria Geral de Apoio à Desestatização do Banco Nacional de Desenvolvimento Econômico e Social. 
BNDES (2000b) - Privatizações no Brasil: 1991-2000 - Secretaria Geral de Apoio à Desestatização do Banco Nacional de Desenvolvimento Econômico e Social.

SINDUSCON/SP (1995) - Construfax, Ano 4, No. 205, de 03 de fevereiro de 1995.

SINDUSCON/SP (1998) - Anuário Paulista da Construção.

Endereços na Internet

Associação Brasileira das Concessionárias de Rodovias - www.abcr.com.br

Associação Brasileira das Concessionárias de Serviços Públicos de Água e Esgoto www.abcon.com.br

Agência Nacional de Energia Elétrica - www.aneel.gov.br 


\section{RESUMOS/ABSTRACTS}

\section{CONSTRUINDO LEIS: OS CONSTRUTORES E AS CONCESSÕES DE SERVIÇOS}

Elementos da teoria da ação coletiva formulada por Mancur Olson - os conceitos de carona e de exploração do grande pelo pequeno - ajudam a explicar o comportamento das entidades que representam os interesses da indústria da construção durante a elaboração da legislação sobre concessões de serviços públicos no Brasil. O artigo contribui para o estudo da articulação de interesses do empresariado durante o processo de produção legislativa de nível federal.

Palavras-chave: lobby; ação coletiva; articulação de interesses

\section{BUILDING LAWS: THE CONSTRUCTORS AND PUBLIC SERVICE CONCESSIONS}

Mancur Olson's theory of collective action - especially his concepts of free-riding and exploitation of the great by the small - helps explain how Brazilian constructors' organ izations behaved while the federal legislation on concession of public services was being made. This article contributes to the study of the articulation of business interests during federal law-making processes.

Keywords: lobby; collective action; interests articulation. 